Check for updates

Cite this: J. Mater. Chem. C, 2021, 9, 3447

Received 22nd January 2021 Accepted 28th January 2021

DOI: $10.1039 / \mathrm{d} 1 \mathrm{tc} 00307 \mathrm{k}$

rsc.li/materials-c

\section{Thermal conductivity reduction by nanostructuration in electrodeposited CuNi alloys $\dagger$}

\author{
Cristina V. Manzano, (D) *ab Olga Caballero-Calero, (D) ${ }^{\mathrm{b}}$ Maxime Tranchant, ${ }^{\mathrm{a}}$ \\ Enrico Bertero, ${ }^{a}$ Pablo Cervino-Solana, iD b Marisol Martin-Gonzalez iD b and \\ Laetitia Philippe iD a
}

\begin{abstract}
In the last few years, the use of inexpensive and scalable materials in industry for thermoelectric applications has received great interest, such as CuNi alloys. In this work, nanocrystalline CuNi alloys with different compositions were grown by pulsed electrodeposition. The incorporation of saccharine in the electrolyte allowed reduction of the crystallite size of CuNi down to 30-40 nm. The thermoelectric properties, such as the electrical conductivity, Seebeck coefficient, and thermal conductivity of these nanocrystalline alloys, were studied. The maximum figure of merit obtained at room temperature was $(6.1 \pm 1.4) \times 10^{-2}$ for nanocrystalline $\mathrm{Cu}_{0.55} \mathrm{Ni}_{0.45}$. The thermal conductivity of $\mathrm{CuNi}$ alloys was reduced by the nanostructuration to a value of $9.0 \pm 0.9 \mathrm{~W} \mathrm{~m}^{-1} \mathrm{~K}^{-1}$, making these nanocrystalline CuNi alloys more competitive than other more classical thermoelectric materials. This work opens a new field to be investigated, that can be described as the use of commercial alloys such as CuNi for thermoelectric applications and shows the use of a new approach to enhance the thermoelectric properties of inexpensive and/or fewer pollutant materials.
\end{abstract}

\section{Introduction}

CuNi alloys have received wide attention due to their interesting mechanical properties ${ }^{1,2}$ (high tensile strength and good wear resistance), anticorrosion, ${ }^{3}$ electrocatalytic, ${ }^{4}$ and electrical properties, ${ }^{5}$ as well as their magnetic properties (which depend on the CuNi composition). ${ }^{1,6}$ The combination of these properties allows the use of these alloys for different applications such as MEMSs (micro-electro-mechanical-systems). ${ }^{7}$ However, their thermoelectric properties have been less studied. ${ }^{8}$

Thermoelectric materials can convert a gradient of temperature into electrical voltage and vice versa. The figure of merit of these materials is defined as $z T$, which is expressed as:

$$
z T=\frac{\sigma^{2}}{k} \times T
$$

where $\sigma$ is the electrical conductivity, $S$ is the Seebeck coefficient, $k$ is the thermal conductivity and $T$ is the absolute temperature. ${ }^{9}$ Many thermoelectric materials are being explored for power

\footnotetext{
${ }^{a}$ Empa, Swiss Faederal Laboratories for Materials Science and Technology, Laboratory for Mechanics of Materials and Nanostructures, Feuerwerkerstrasse 39, CH-3602 Thun, Switzerland. E-mail: cristina.vicente@csic.es

${ }^{b}$ Instituto de Micro y Nanotecnología, IMN-CNM, CSIC (CEI UAM+CSIC) Isaac Newton, 8, E-28760, Tres Cantos, Madrid, Spain

$\dagger$ Electronic supplementary information (ESI) available. See DOI: 10.1039/ d1 tc00307k
}

generation applications, such as GeTe, ${ }^{10,11} \mathrm{PbTe}^{12}{ }^{12} \mathrm{Bi}_{2} \mathrm{Te}_{3},{ }^{13-19}$ and silicide. ${ }^{20}$ Among CuNi alloys, Constantan $\left(\mathrm{Cu}_{55} \mathrm{Ni}_{45}\right)$ is known to be an excellent electrical conductor $\left(\sim 2(\mu \Omega \mathrm{m})^{-1}\right.$ at RT) and to have a decent Seebeck coefficient $\left(\sim-45\right.$ or $-50 \mu \mathrm{V} \mathrm{K}{ }^{-1}$, at RT and $-70 \mu \mathrm{V} \mathrm{K}^{-1}$ at $1100 \mathrm{~K}$ ) when compared to conventional thermoelectric materials. ${ }^{8,21}$ These two values allow this CuNi alloy to have an ultrahigh power factor $\left(10290 \mu \mathrm{W} \mathrm{m}{ }^{-1} \mathrm{~K}^{-2}\right.$ at $\left.1100 \mathrm{~K}\right),{ }^{21}$ which makes it a good candidate for power generation. The maximum power of $21 \mu \mathrm{W}$ has been demonstrated in devices consisting of 15-pairs of thin-film $\mathrm{Cu} / \mathrm{CuNi}$ thermoelectric generators, ${ }^{22}$ and is comparable to those of semiconductor thermoelectric modules such as those based on $\mathrm{Bi}_{2} \mathrm{Te}_{3}$ alloys, which is one of the most used thermoelectric materials for room temperature applications. Also, it is a good candidate for cooling, since a giant Peltier cooling effect has been measured in $\mathrm{CuNi}$ and $\mathrm{Au}$ junctions. The reported significant cooling-power density of these junctions is above $2 \times 10^{8} \mathrm{~W} \mathrm{~cm}^{-2}$, which is several orders of magnitude higher than a commercial Peltier-cooling devices $\left(10 \mathrm{~W} \mathrm{~cm}^{-2}\right) .{ }^{23} \mathrm{How}^{-}$ ever, the main drawback of these CuNi alloys to become competitive versus other commercial semiconductors is that these alloys present very high thermal conductivity $\left(\sim 29 \mathrm{~W} \mathrm{~m}^{-1} \mathrm{~K}^{-1}\right.$ at $300 \mathrm{~K}$ and $60 \mathrm{~W} \mathrm{~m}^{-1} \mathrm{~K}^{-1}$ at $1100 \mathrm{~K}^{21}$ ). This makes the figure of merit low, approximately $5 \times 10^{-2}$ at room temperature. ${ }^{21}$ In the last 30 years, the thermoelectric community has learned that nanostructuration can help to reduce the thermal conductivity of a great variety of materials. If they are properly prepared, these 
nanostructured thermoelectric materials can maintain the original power factor, ${ }^{24,25}$ while reducing the thermal conductivity. This is the main objective of this work.

The LIGA (German acronym for Lithography, Electroplating, and Moulding) process is a good candidate for the fabrication of thermoelectric devices. ${ }^{26}$ The advantage of using UV-lithography is that free-standing samples without the conductive substrate necessary to perform the electrodeposition are obtained. Normally, the electrodeposited films should be transferred to a nonconductive substrate and during this transfer, some cracks can be created in the material, which can affect the final electrical performance of the film. For this reason, free-standing CuNi alloys have been electrodeposited using the LIGA process. To reduce the crystallite size during the LIGA process certain additives are added to the electrochemical bath such as saccharine, ${ }^{3,26,27}$ sodium lignosulfonate, ${ }^{28,29}$ etc. It is also important to mention that $\mathrm{Ni}$ and Ni alloys do not present thermal stability due to the increase in grain size with time. ${ }^{30}$ Then, to solve this problem, it is mandatory to control the growth of nanocrystalline alloys, for example using organic additives, ${ }^{31}$ such as saccharine, to avoid the growth of grain size, while having thermal stability. In the literature, few studies are reported based on the growth of electrodeposited finegrained $^{3,30,32}$ or nanocrystalline ${ }^{26,31}$ deposits. The thermoelectric properties of CuNi alloys have not been addressed in these studies.

This study aims at investigating the effect of nanostructuration on the thermoelectric properties of CuNi alloys with different compositions by using an economic, industrially known, and scalable fabrication method such as electrodeposition combined with UV-lithography. This study is therefore focused on the electrodeposition of nanocrystalline CuNi alloys with different compositions through controlled pulsed electrodeposition and the incorporation of saccharine in the electrolyte to obtain nanostructured CuNi alloys. The thermoelectric properties, electrical conductivity, Seebeck coefficient, and thermal conductivity, of these CuNi alloys, have been analysed.

\section{Experimental methods}

\subsection{Fabrication using UV-lithography}

UV-lithography moulds were fabricated using $\langle 100\rangle$ single-crystal Si wafers. To perform the electrodeposition inside the moulds, $5 \mathrm{~nm} \mathrm{Cr}$ and $100 \mathrm{~nm} \mathrm{Au}$ were deposited using Alliance-Concept DP 650 DC magnetron sputtering. High viscosity SU-8 (GM 1075, Gersteltec Sarl) was spin-coated and the desired pattern was exposed using a Karl Suss MA6 contact aligner. The exposure light source was filtered above $365 \mathrm{~nm}$ and it irradiated the polymer with $8.1 \mathrm{~mW} \mathrm{~cm}^{-2}$ intensity. A post-exposure bake was performed, and then immersion in propylene glycol methyl ether acetate (PGMEA, Sigma Aldrich) was used to dissolve the unexposed SU-8. The final mould obtained was used to create strips of $1.2 \mathrm{~cm} \times 0.6 \mathrm{~cm}$ with a height of $80 \mu \mathrm{m}$.

\subsection{Electrodeposition of nanocrystalline CuNi alloys}

CuNi alloys were electrodeposited in a vertical electrochemical cell consisting of three electrodes, the UV-lithography mould as the working electrode, a Pt mesh as the counter electrode, and $\mathrm{Ag} / \mathrm{AgCl}$ as the working electrode. The electrodeposition process was carried out using a potentiostat-galvanostat (Eco Chemie, Model AUT302N), and an electrochemical cell with a double wall jacket cell to control the electrodeposition temperature; the working temperature was $45 \pm 1{ }^{\circ} \mathrm{C}$. The electrolyte used to perform the electrodeposition was an aqueous solution, which contained $0.3 \mathrm{M} \mathrm{NiSO}_{4} \cdot 6 \mathrm{H}_{2} \mathrm{O}(98 \%$, Sigma Aldrich), $0.08 \mathrm{M}$ $\mathrm{CuSO}_{4} \cdot 5 \mathrm{H}_{2} \mathrm{O}$ (99\%, Sigma Aldrich), $0.2 \mathrm{M} \mathrm{C}_{6} \mathrm{H}_{5} \mathrm{Na}_{3} \mathrm{O}_{7} \cdot 2 \mathrm{H}_{2} \mathrm{O}$ (99\%, Sigma Aldrich), 0.7 mM SDS (97\%, Sigma Aldrich), and $10.9 \mathrm{mM}$ saccharine (99\%, Sigma Aldrich). Sodium citrate $\left(\mathrm{C}_{6} \mathrm{H}_{5} \mathrm{Na}_{3} \mathrm{O}_{7} \cdot 2 \mathrm{H}_{2} \mathrm{O}\right)$ was used as a complexing agent, saccharine to decrease the grain size of the alloy, and sodium dodecylsulfate (SDS) as a wetting agent. ${ }^{1}$ The $\mathrm{pH}$ of the solution was 6 to avoid the precipitation of copper during the electrodeposition. ${ }^{32}$ The alloys were electroplated with a current thief to enhance the homogeneity of the deposit in terms of thickness and composition. The pulsed galvanostatic deposition was carried out between a certain current density and zero current density. Different $t_{\text {on }}$ and $t_{\text {off }}$ were studied to reduce the internal stress as much as possible. The best results were found when $t_{\mathrm{on}}=0.3 \mathrm{~s}$ and $t_{\text {off }}=3 \mathrm{~s}$.

The alloys were then polished to obtain a mirror surface finish. 1200 and 2500 polishing papers along with different sized alumina particles $(6,1,0.3$, and $0.05 \mu \mathrm{m})$ from Buehler ${ }^{\mathbb{R}}$ were employed. $0.04 \mu \mathrm{m} \mathrm{SiO}_{2}$ particles were also used to avoid copper oxidation after polishing. To obtain a free-standing thick-film, Si, Cr, and $\mathrm{Au}$ substrates were removed using $2 \mathrm{M}$ $\mathrm{KOH}$ at $50{ }^{\circ} \mathrm{C}$ overnight, $0.25 \mathrm{M} \mathrm{KMnO}_{4}$ and $0.5 \mathrm{M} \mathrm{NaOH}$ aqueous solution at room temperature for some seconds, and $\mathrm{Au}$ etchant (from Sigma Aldrich, Ni compatible) for some seconds, respectively. After this procedure, free-standing CuNi thick-films were obtained.

\subsection{Compositional, morphological, and structural characterization of nanocrystalline CuNi alloys}

The composition of CuNi alloys was analysed using an XRF (X-ray Fluorescence) system from Fisherscope X-ray XDV. Energy dispersive X-ray (EDX) spectroscopy was used to study the uniformity of the composition along the cross-section of the alloys using an S-3000 N EDX with $20 \mathrm{kV}$ accelerating voltage. Morphological characterization of the cross-section of the alloys was performed using a Field Emission-Scanning Electron Microscope (FE-SEM, FEI VERIOS 460) with a $2 \mathrm{kV}$ accelerating voltage. Structural characterization of the nanocrystalline CuNi alloys was carried out using high-resolution X-ray diffraction (XRD). The measurements were performed using a Philips $\mathrm{X}$ 'Pert four-circle diffractometer system in the Bragg-Brentano configuration with $\mathrm{CuK}_{\alpha}$ radiation.

\subsection{Thermoelectric properties of nanocrystalline CuNi alloys}

The electrical conductivity, $\sigma$, and Seebeck coefficient, $S$, of the CuNi alloys were measured in-plane as a function of the temperature, from $25{ }^{\circ} \mathrm{C}$ to $800{ }^{\circ} \mathrm{C}$. The values of the electrical conductivity at room temperature were obtained using a commercial Hall Ecopia HMS-5500 system; while the Seebeck 
coefficient at room temperature was measured using a labmade system. The electrical conductivity and Seebeck coefficient from $75-800{ }^{\circ} \mathrm{C}$ were characterized using a commercial LSR-3 Linseis system. To stabilize the temperature gradient at the set temperature and improve the accuracy, multiple measurements were performed at each temperature. The experimental errors associated with these thermoelectric properties are $5 \%$ and $10 \%$ for the electrical conductivity and Seebeck coefficient, respectively. From these two magnitudes, $\sigma$ and $S$, the power factor, PF, was calculated as a function of the temperature; where $\mathrm{PF}=\sigma \cdot S{ }^{2}$

The out-of-plane thermal conductivity was measured with a photoacoustic (PA) system at room temperature. This system is based on the detection, with the aid of a lock-in amplifier, of the phase shift between two signals: the first one periodically heats the surface of the sample with a modulated laser (Alphalas, fibercoupled, $980 \mathrm{~nm}$ wavelength and $260 \mathrm{~mW}$ intensity) and the second is the acoustic signal produced by the expansion and contraction of the air in contact with the surface of the sample and detected using a microphone (40 BL 1/4 CCP pressure type, with a $26 \mathrm{CB}, 1 / 4$ preamplifier, both from G.R.A.S. Sound \& Vibration). This phase shift is compared with the one obtained from performing the same experiment on a reference signal (a quartz substrate with $80 \mathrm{~nm}$ of titanium evaporated on its surface as a transductor). Knowing these phase-shifts, and using the multilayer model developed by $\mathrm{Hu}$ et al. ${ }^{33}$ the actual thermal properties of the sample can be obtained. The PA technique gives the thermal diffusivity, $\alpha$, and then the thermal conductivity, $k$, is calculated using the theoretical density, $\rho$, and specific heat, $C_{\mathrm{p}}$, which depend on the CuNi composition by the following equation: $k=\alpha \cdot \rho \cdot C_{\mathrm{p}}$. The error of the thermal conductivity measurements by the PA technique is approximately $10 \% .{ }^{14,34}$ This technique has previously been used to measure the thermal conductivity of electrodeposited films. ${ }^{29}$

\section{Results and discussion}

\subsection{Electrodeposition of nanocrystalline CuNi alloys}

One of the largest challenges in producing CuNi alloys inside LIGA moulds is to control the internal stress within the alloys. In our case, the internal stress was controlled using pulsed electrodeposition, and adjusting the electrodeposition temperature and saccharine concentration. ${ }^{26}$ The pulsed galvanostatic deposition was performed at a certain current density $\left(-20,-60\right.$, and $\left.-90 \mathrm{~mA} \mathrm{~cm}^{-2}\right)$ for $0.3 \mathrm{~s}$ and zero current density for $3 \mathrm{~s}$. The total deposition time was 17,15 , and $6 \mathrm{~h}$ for -20 , -60 , and $-90 \mathrm{~mA} \mathrm{~cm}^{-2}$, respectively. As is shown in the optical image of Fig. 1, the CuNi alloys are free-standing samples.

\subsection{Compositional, morphological, and structural characterization of nanocrystalline CuNi alloys}

The composition of CuNi was studied using XRF. The materials grown at a current density of $-20,-60$, and $-90 \mathrm{~mA} \mathrm{~cm} \mathrm{~cm}^{-2}$ present compositions of $\mathrm{Cu}_{0.67} \mathrm{Ni}_{0.33}, \mathrm{Cu}_{0.57} \mathrm{Ni}_{0.43}$, and $\mathrm{Cu}_{0.46} \mathrm{Ni}_{0.54}$, respectively. To study the uniformity of the composition along the cross-section of the alloys, EDX analysis was performed along the thickness of the alloys. The composition, measured using EDX

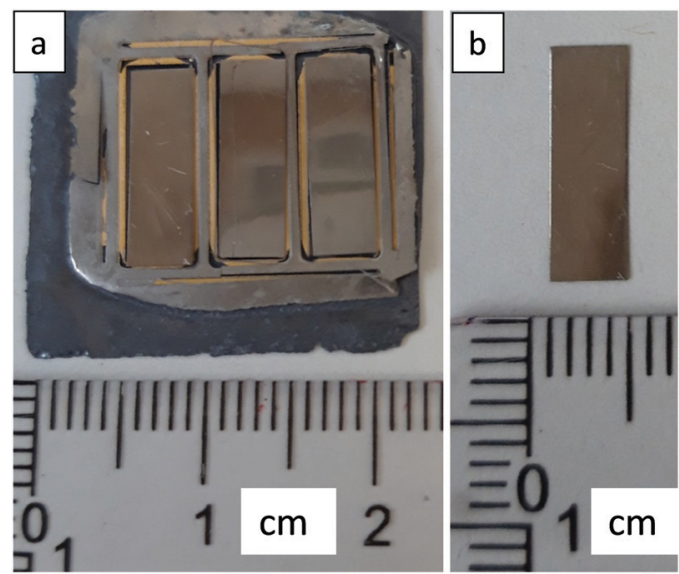

Fig. 1 (a) Optical images of CuNi alloys inside the moulds, and (b) optical images of a free-standing CuNi alloy.

(at\%), was $\mathrm{Cu}_{0.65} \mathrm{Ni}_{0.35}, \mathrm{Cu}_{0.55} \mathrm{Ni}_{0.45}$, and $\mathrm{Cu}_{0.45} \mathrm{Ni}_{0.55}$ for a current density of $-20,-60$, and $-90 \mathrm{~mA} \mathrm{~cm}{ }^{-2}$, respectively. Given that the EDX measurements are more accurate than XRF measurements, the compositions of CuNi alloys considered will be those found by the EDX technique.

Fig. 2 shows the FE-SEM cross-section of CuNi alloys; the morphology is granular for $\mathrm{Cu}_{0.65} \mathrm{Ni}_{0.35}$ and $\mathrm{Cu}_{0.55} \mathrm{Ni}_{0.45}$, the grain size being bigger in the case of the higher copper content $\left(\mathrm{Cu}_{0.65} \mathrm{Ni}_{0.35}\right)$. The morphology of $\mathrm{Cu}_{0.45} \mathrm{Ni}_{0.55}$ is columnar, as it is the typical growth of $\mathrm{Ni}$. When the $\mathrm{Cu}$ content is higher than 0.50 , the morphology is more granular, and when the Ni content is higher than 0.50, it becomes columnar. From the FE-SEM images (see Fig. 2), the thicknesses of the alloys can be extracted, being approximately 34,23 , and $30 \mu \mathrm{m}$ for $\mathrm{Cu}_{0.65} \mathrm{Ni}_{0.35}, \mathrm{Cu}_{0.55} \mathrm{Ni}_{0.45}$, and $\mathrm{Cu}_{0.45} \mathrm{Ni}_{0.55}$, respectively.

To know the crystallographic structure and crystallite size of the studied alloys, XRD measurements were performed. Fig. 3 shows the X-ray diffractograms of the alloys grown at galvanostatic pulsed deposition. The different peaks that can be seen can be associated with CuNi (JCPDS 09-0205). All the alloys present three diffraction peaks, (111), (200), and (220).

To obtain the degree of preferred orientation quantitatively, we have performed the Harris texture analysis. ${ }^{35}$ The equation of the texture coefficient is:

$$
\mathrm{TC}_{(h k l)}=\frac{\frac{I_{(h k l)}}{I_{(h k l)}^{0}}}{\frac{1}{N} \sum \frac{I_{(h k l)}}{I_{(h k l)}^{0}}}
$$

where $I_{(h k l)}$ and $I_{(h k l)}^{0}$ are the intensity of a generic peak observed in the experimental XRD and the literature value from the database (JCPDS $=09-0205$ ), respectively, and $N$ is the number of reflections considered in the analysis. The standard deviation $\left(\sigma_{\mathrm{TC}}\right)$ indicates the deviation intensity of the experimental $\mathrm{XRD}$ from published values of JCPDS and is calculated as:

$$
\sigma_{\mathrm{TC}}=\sqrt{\frac{\sum\left(\mathrm{TC}_{(h k l)}-1\right)^{2}}{N}}
$$



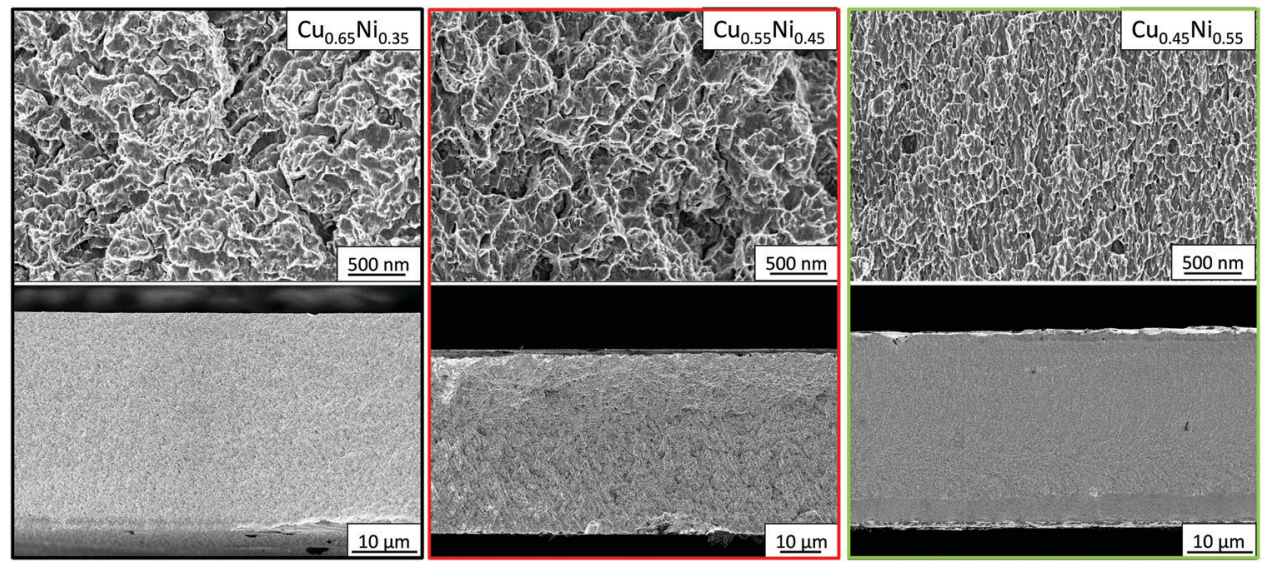

Fig. 2 FE-SEM micrographs of cross-sections of CuNi alloys with different compositions

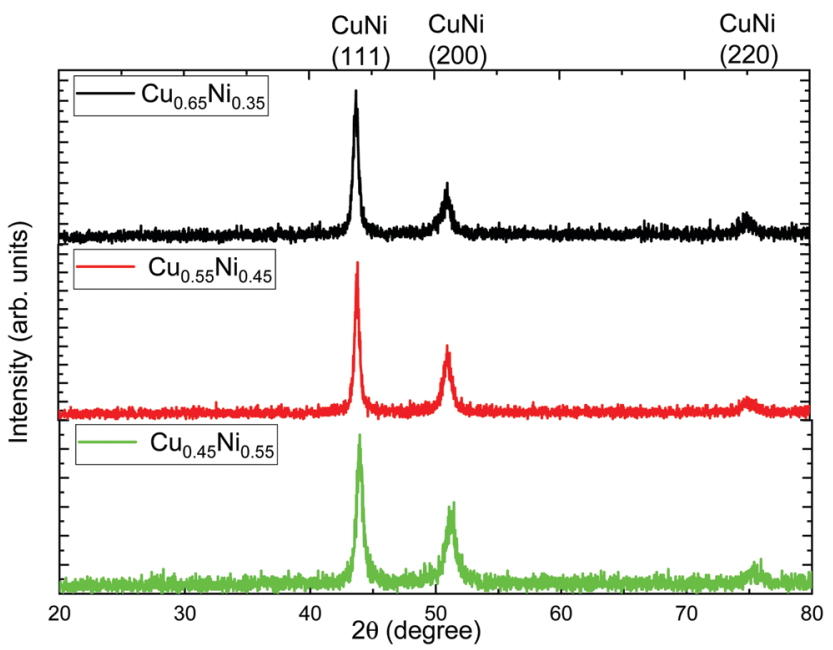

Fig. 3 X-ray diffractograms of nanocrystalline CuNi alloys with different compositions.

The values of the texture coefficient and its standard deviation are collected in Table 1.

According to the texture coefficients, the alloys are polycrystalline, with a crystallographic orientation along [200] and [220] directions. To know if the CuNi alloys are nanocrystalline, the crystallite size in the (111) diffraction peak was calculated using the Debye-Scherrer equation:

$$
D=\frac{0.9 \cdot \lambda}{\beta \cdot \cos \theta}
$$

where $D$ is the crystallite size, $\lambda$ is the radiation wavelength, $\beta$ is the line broadening at full width at half maximum (FWHM) of the intense peak, and $\theta$ is the Bragg angle. All the CuNi alloys present a crystallite size between 30 and $40 \mathrm{~nm}$ (see Table 1), confirming that CuNi alloys grown in this work are nanocrystalline.

\subsection{Thermoelectric properties of nanocrystalline CuNi alloys}

Fig. 4 shows the thermoelectric properties of CuNi alloys with different compositions. The thermoelectric figure of merit $(z \cdot T=$ $\left.\left(\sigma \cdot S^{2} / k\right) \cdot T\right)$ at room temperature $(298.15 \mathrm{~K})$ is plotted as a function of the composition of the alloys in Fig. 4a. This magnitude was found to be $(5.5 \pm 1.5) \times 10^{-2},(6.1 \pm 1.4) \times 10^{-2}$, and $(5.9 \pm 1.4) \times 10^{-2}$ for $\mathrm{Cu}_{0.65} \mathrm{Ni}_{0.35}, \mathrm{Cu}_{0.55} \mathrm{Ni}_{0.45}$, and $\mathrm{Cu}_{0.45} \mathrm{Ni}_{0.55}$, respectively. Certain thermoelectric materials have a strong anisotropy in the electrical and thermal conductivities ${ }^{14}$ that avoids $z T$ calculations when the materials are measured in different crystallographic directions. This anisotropy is related to the crystallographic structure. In this case, the CuNi alloys present a cubic structure, which implies that the alloy should have isotropic properties on any axis. In our case, the alloys have a slightly preferred orientation along the [100] and [110] directions but since it is a cubic crystallographic structure, the material should be isotropic. For this reason, it is considered that the $z T$ of the CuNi alloys can be calculated in this specific case, regardless of whether the electrical conductivity has been measured in-plane and the thermal conductivity has been measured out-of-plane. This $z T$ value is 1.3 times higher than the value observed in the literature $\left(5 \times 10^{-2}\right)$ at room temperature ${ }^{21}$ in the case of bulk CuNi material.

The electrical conductivity at $25{ }^{\circ} \mathrm{C}$ was found to be $1.13 \pm$ $0.06(\mu \Omega \mathrm{m})^{-1}, 1.25 \pm 0.06(\mu \Omega \mathrm{m})^{-1}$, and $1.34 \pm 0.07(\mu \Omega \mathrm{m})^{-1}$ for $\mathrm{Cu}_{0.65} \mathrm{Ni}_{0.35}, \mathrm{Cu}_{0.55} \mathrm{Ni}_{0.45}$, and $\mathrm{Cu}_{0.45} \mathrm{Ni}_{0.55}$, respectively. The electrical conductivity as a function of the temperature (from 70 to $800{ }^{\circ} \mathrm{C}$ ) is shown in Fig. 3c. The maximum values of the electrical conductivity were $1.66 \pm 0.08(\mu \Omega \mathrm{m})^{-1}$ at $250-415^{\circ} \mathrm{C}$, $1.39 \pm 0.07(\mu \Omega \mathrm{m})^{-1}$ at $315-365^{\circ} \mathrm{C}$, and $1.49 \pm 0.07(\mu \Omega \mathrm{m})^{-1}$ at $75{ }^{\circ} \mathrm{C}$ for $\mathrm{Cu}_{0.65} \mathrm{Ni}_{0.35}, \mathrm{Cu}_{0.55} \mathrm{Ni}_{0.45}$, and $\mathrm{Cu}_{0.45} \mathrm{Ni}_{0.55}$, respectively. The maximum value is observed for the CuNi alloy with $65 \% \mathrm{Cu}$, while the two other alloys present approximately similar electrical conductivity values within the experimental error. The electrical conductivity decreases approximately at $450{ }^{\circ} \mathrm{C}$ and to a greater extent at $600{ }^{\circ} \mathrm{C}$, the latter reduction being stronger, reaching a minimum electrical conductivity value at $800{ }^{\circ} \mathrm{C}$, which is $0.3(\mu \Omega \mathrm{m})^{-1}$ lower than the maximum value.

Compared with the literature, an electrical conductivity value of $2.2(\mu \Omega \mathrm{m})^{-1}$ at room temperature for $\mathrm{Cu}_{0.60} \mathrm{Ni}_{0.40}$ films electrodeposited on silicon substrates ${ }^{8}$ was reported, a constant electrical conductivity value at temperature (from 300 to $1100 \mathrm{~K}$ ) of $2.1(\mu \Omega \mathrm{m})^{-1}$ was observed for non-nanocrystalline $\mathrm{Cu}_{0.55} \mathrm{Ni}_{0.45}$ bulk material, ${ }^{21}$ and theoretically a value of $3(\mu \Omega \mathrm{m})^{-1}$ was 
Table 1 Harris texture coefficient, standard deviation, FWHM, and crystallite size of CuNi alloys with different compositions

\begin{tabular}{|c|c|c|c|c|c|c|c|}
\hline Composition & Peak $(h k l)$ & Intensity XRD & Intensity JCPDS & $\begin{array}{l}\text { Texture coefficient } \\
\left(\mathrm{TC}_{(h k l)}\right)\end{array}$ & $\begin{array}{l}\text { Standard } \\
\text { deviation }\left(\sigma_{\mathrm{TC}}\right)\end{array}$ & FWHM (111) & Crystallite size $(\mathrm{nm})$ \\
\hline \multirow[t]{2}{*}{$\mathrm{Cu}_{0.65} \mathrm{Ni}_{0.35}$} & 111 & 250 & 100 & 0.45 & \multirow[t]{2}{*}{0.41} & \multirow[t]{2}{*}{0.51} & \multirow[t]{2}{*}{27} \\
\hline & 200 & 101 & 45 & 1.13 & & & \\
\hline \multirow[t]{2}{*}{$\mathrm{Cu}_{0.55} \mathrm{Ni}_{0.45}$} & 111 & 286 & 100 & 0.35 & \multirow[t]{2}{*}{0.51} & \multirow[t]{2}{*}{0.39} & \multirow[t]{2}{*}{38} \\
\hline & 200 & 104 & 45 & 1.05 & & & \\
\hline \multirow{3}{*}{$\mathrm{Cu}_{0.45} \mathrm{Ni}_{0.55}$} & 111 & 337 & 100 & 0.44 & \multirow[t]{3}{*}{0.48} & \multirow[t]{3}{*}{0.49} & \multirow[t]{3}{*}{30} \\
\hline & 200 & 112 & 45 & 0.94 & & & \\
\hline & 220 & 54 & 23 & 1.62 & & & \\
\hline
\end{tabular}
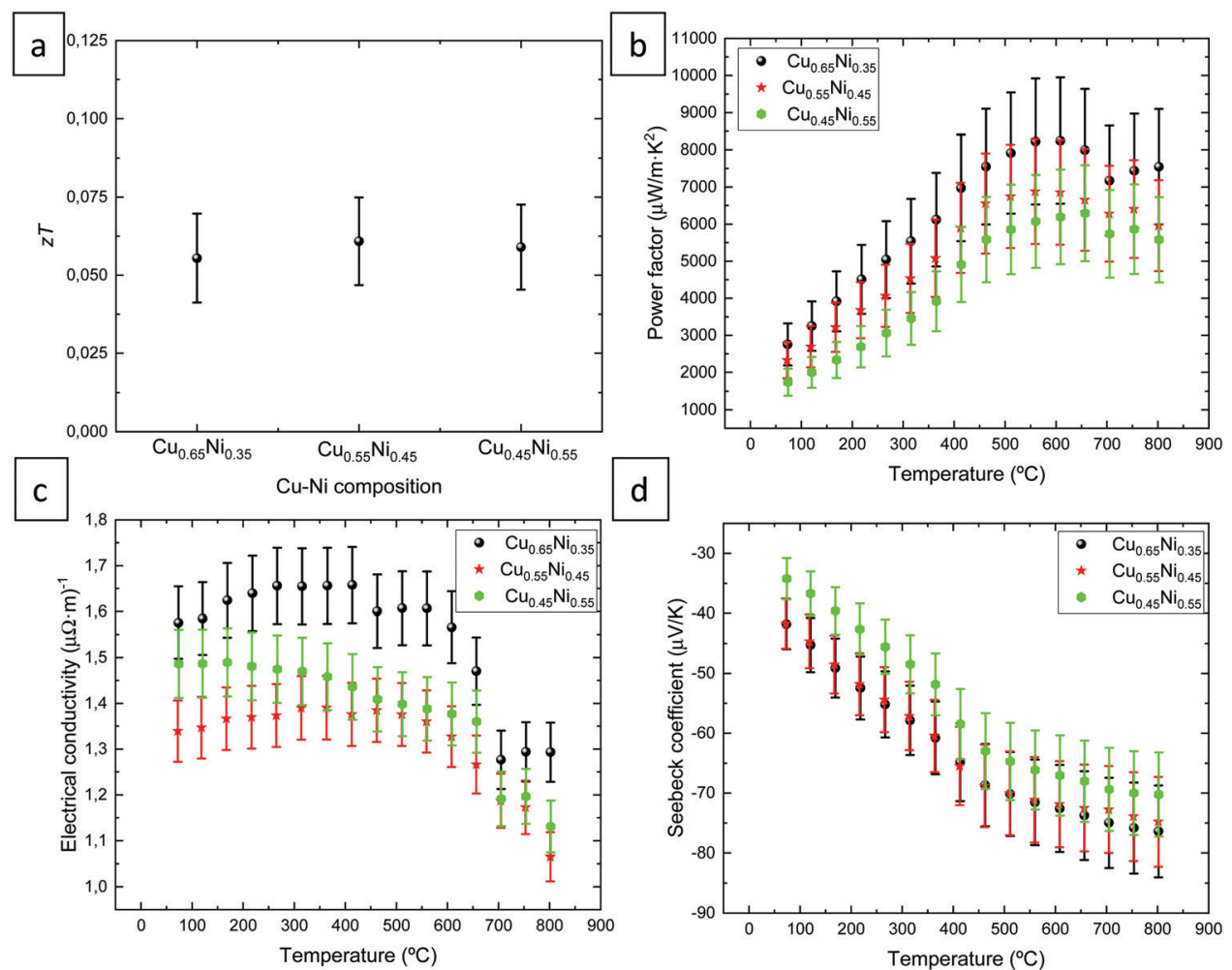

d

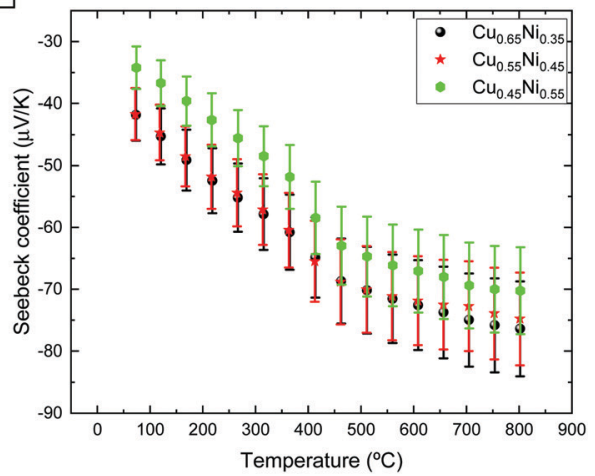

Fig. 4 Thermoelectric properties of nanocrystalline CuNi alloys with different compositions. (a) Figure of merit, (b) power factor, (c) electrical conductivity, and (d) Seebeck coefficient.

obtained for CuNi alloys in a study where they analysed different thermoelectric materials with resonant levels. ${ }^{36}$ These experimental values are 1.4 times higher than the maximum values obtained in this present study. This reduction in the electrical conductivity is due to the reduction in the crystallite size of the CuNi materials observed by XRD, which in this case is around 30-40 nm. However, these electrical conductivity values are similar to the values obtained for porous and nanostructured $\mathrm{Ni}_{1-x} \mathrm{Cu}_{x}$ alloys grown by a modified hydrothermal method. ${ }^{37}$

Fig. 4 shows a slight increase in the electrical conductivity that can be due to the start of the crystallization of the CuNi alloy. It is important to note that the electrodeposited CuNi alloys are grown at a temperature close to room temperature. As observed in Fig. 4, the reduction in the electrical conductivity after $600{ }^{\circ} \mathrm{C}$ is due to a change in the crystallographic structure, crystallite size, and morphology of the alloys. After the thermoelectric measurements in temperature, XRD, and FE-SEM were performed. As shown in the XRD diffractograms and texture coefficients (see Fig. S1 and Table S1 in the ESI $\dagger$ ) the alloys are still polycrystalline, but now with different crystallographic orientations. A crystallographic orientation along [200] and [111] directions was found for $\mathrm{Cu}_{0.65} \mathrm{Ni}_{0.35}$, [220] and [200] directions for $\mathrm{Cu}_{0.55} \mathrm{Ni}_{0.45}$, and [111], [220], and [200] for $\mathrm{Cu}_{0.45} \mathrm{Ni}_{0.55}$ after the measurements. The crystallite size after the thermoelectric measurements at temperature was found to be 91,73 , and $83 \mathrm{~nm}$ for $\mathrm{Cu}_{0.65} \mathrm{Ni}_{0.35}, \mathrm{Cu}_{0.55} \mathrm{Ni}_{0.45}$, and $\mathrm{Cu}_{0.45} \mathrm{Ni}_{0.55}$, respectively. Then, the crystallite size grew from 30-40 $\mathrm{nm}$ to $70-90 \mathrm{~nm}$ after the measurements. SEM images 
Table 2 Measured electrical and thermal conductivities for the different compositions studied in this work and $\mathrm{Cu}_{0.55} \mathrm{Ni}_{0.45}$ bulk alloy ${ }^{21}$ are presented, along with the calculated electronic and lattice thermal conductivities associated with each of them

\begin{tabular}{lllll}
\hline Composition & $\sigma(\Omega \mathrm{m})^{-1}$ & $k\left(\mathrm{~W} \mathrm{~m}^{-1} \mathrm{~K}^{-1}\right)$ & $k_{\mathrm{e}}\left(\mathrm{W} \mathrm{m}^{-1} \mathrm{~K}^{-1}\right)$ & $8.2 \pm 0.4$ \\
\hline $\mathrm{Cu}_{0.65} \mathrm{Ni}_{0.35}$ & $(1.13 \pm 0.06) \times 10^{6}$ & $9.1 \pm 0.9$ & $9.1 \pm 0.4$ & $0.9 \pm 0.4$ \\
$\mathrm{Cu}_{0.55} \mathrm{Ni}_{0.45}$ & $(1.25 \pm 0.06) \times 10^{6}$ & $11.8 \pm 1.2$ & $9.7 \pm 0.4$ & $2.7 \pm 0.4$ \\
$\mathrm{Cu}_{0.45} \mathrm{Ni}_{0.55}$ & $(1.34 \pm 0.07) \times 10^{6}$ & $11.5 \pm 1.2$ & 15.4 & $1.8 \pm 0.4$ \\
$\mathrm{Cu}_{0.55} \mathrm{Ni}_{0.45}$ bulk $^{21}$ & $2.1 \times 10^{6}$ & 29 &
\end{tabular}

(see Fig. S2 in the ESI $\dagger$ ) show a morphology similar for the three alloys after carrying out the measurements until $800{ }^{\circ} \mathrm{C}$, where the morphology presented terraces.

Fig. 4d shows the Seebeck coefficient as a function of the temperature (from $70{ }^{\circ} \mathrm{C}$ to $800{ }^{\circ} \mathrm{C}$ ). The minimum Seebeck coefficient values were observed in the case of $\mathrm{Cu}_{0.45} \mathrm{Ni}_{0.55}$, while for the other two alloys, $\mathrm{Cu}_{0.65} \mathrm{Ni}_{0.35}$ and $\mathrm{Cu}_{0.55} \mathrm{Ni}_{0.45}$, the Seebeck coefficient is similar. For all CuNi material, the maximum Seebeck coefficient is reached at $800{ }^{\circ} \mathrm{C}$, the values of this magnitude were found to be $-76 \pm 8,-75 \pm 8$, and $-70 \pm 7 \mu \mathrm{V} \mathrm{K}^{-1}$ for $\mathrm{Cu}_{0.65} \mathrm{Ni}_{0.35}$, $\mathrm{Cu}_{0.55} \mathrm{Ni}_{0.45}$, and $\mathrm{Cu}_{0.45} \mathrm{Ni}_{0.55}$, respectively. The Seebeck coefficient is negative, indicating the n-type conduction of the material. However, the lowest Seebeck coefficient was observed at room temperature, $25{ }^{\circ} \mathrm{C}$. The values of the Seebeck coefficient at this temperature were $-39 \pm 4,-44 \pm 4$, and $-41 \pm 4 \mu \mathrm{V} \mathrm{K}^{-1}$ for $\mathrm{Cu}_{0.65} \mathrm{Ni}_{0.35}, \mathrm{Cu}_{0.55} \mathrm{Ni}_{0.45}$, and $\mathrm{Cu}_{0.45} \mathrm{Ni}_{0.55}$, respectively. The Seebeck coefficient values found in the literature are $-45 \mu \mathrm{V} \mathrm{K}^{-1}$ at RT for $\mathrm{Cu}_{0.60} \mathrm{Ni}_{0.40}$ electrodeposited films, ${ }^{8}-50 \mu \mathrm{V} \mathrm{K}{ }^{-1}$ at $300 \mathrm{~K}$ and $-70 \mu \mathrm{V} \mathrm{K} \mathrm{K}^{-1}$ at $1100 \mathrm{~K}$ for non-nanocrystalline $\mathrm{Cu}_{0.55} \mathrm{Ni}_{0.45}$ material $^{21}$ and $-40 \mu \mathrm{V} \mathrm{K}{ }^{-1}$ theoretically. ${ }^{36}$ These values are approximately 1.1 higher than the values obtained in this study at room temperature.

The thermoelectric power factor as a function of the temperature (from $70{ }^{\circ} \mathrm{C}$ to $800{ }^{\circ} \mathrm{C}$ ) is shown in Fig. 4c. The maximum value is observed for the CuNi alloy with $65 \%$ of $\mathrm{Cu}$, while the $\mathrm{CuNi}$ material with $45 \%$ of $\mathrm{Cu}$ exhibits the lowest values, suggesting that when the $\mathrm{Cu}$ content is higher, the thermoelectric power factor is higher. The maximum power factor values were obtained between $560-660{ }^{\circ} \mathrm{C}$, these values were found to be $8248 \pm 1700 \mu \mathrm{W} \mathrm{m}{ }^{-1} \mathrm{~K}^{-2}$ at $610{ }^{\circ} \mathrm{C}, 6880 \pm 1400 \mu \mathrm{W} \mathrm{m}^{-1} \mathrm{~K}^{-2}$ at $560{ }^{\circ} \mathrm{C}$, and $6292 \pm 1300 \mu \mathrm{W} \mathrm{m}{ }^{-1} \mathrm{~K}^{-2}$ at $660{ }^{\circ} \mathrm{C}$ for $\mathrm{Cu}_{0.65} \mathrm{Ni}_{0.35}$, $\mathrm{Cu}_{0.55} \mathrm{Ni}_{0.45}$, and $\mathrm{Cu}_{0.45} \mathrm{Ni}_{0.55}$, respectively. The values of the power factor at room temperature were $1673 \pm 396,2387 \pm 492$, and $2275 \pm 469 \mu \mathrm{W} \mathrm{m}{ }^{-1} \mathrm{~K}^{-2}$ for $\mathrm{Cu}_{0.65} \mathrm{Ni}_{0.35}, \mathrm{Cu}_{0.55} \mathrm{Ni}_{0.45}$, and $\mathrm{Cu}_{0.45} \mathrm{Ni}_{0.55}$, respectively. The maximum value at room temperature is observed for the CuNi alloy with $55 \%$ of $\mathrm{Cu}$, but all the alloys present similar values considering the experimental errors. It seems that the CuNi alloys grown in this study are thermally stable up to approximately $600{ }^{\circ} \mathrm{C}$.

When the power factor is compared to that found in the literature, a value of $5500 \mu \mathrm{W} \mathrm{m}{ }^{-1} \mathrm{~K}^{-1}$ at room temperature for $\mathrm{Cu}_{0.60} \mathrm{Ni}_{0.40}$ electrodeposited films ${ }^{8}$ was observed, values between $5250 \mu \mathrm{W} \mathrm{m}{ }^{-1} \mathrm{~K}^{-2}$ at $300 \mathrm{~K}$ and $10290 \mu \mathrm{W} \mathrm{m}{ }^{-1} \mathrm{~K}^{-2}$ at $1100 \mathrm{~K}$ in the case of non-nanocrystalline $\mathrm{Cu}_{0.55} \mathrm{Ni}_{0.45}$ material, ${ }^{21}$ and theoretical value of $4800 \mu \mathrm{W} \mathrm{m}{ }^{-1} \mathrm{~K}^{-2} \cdot{ }^{36}$ The maximum thermoelectric power factor is the one obtained at $1100 \mathrm{~K}\left(10290 \mu \mathrm{W} \mathrm{m}{ }^{-1} \mathrm{~K}^{-2}\right){ }^{21}$ which is 1.2 higher than the value observed in this study. When comparing the maximum power factor observed in literature for nanostructured $\mathrm{CuNi}$ alloys, $5530 \mu \mathrm{W} \mathrm{m}{ }^{-1} \mathrm{~K}^{-2}$ at $300{ }^{\circ} \mathrm{C}$ for $\mathrm{Cu}_{50} \mathrm{Ni}_{50},{ }^{38}$ our value at this temperature is $5600 \mu \mathrm{W} \mathrm{m}{ }^{-1} \mathrm{~K}^{-2}$ for $\mathrm{Cu}_{65} \mathrm{Ni}_{35}$; indicating that both values are very close.

The thermal conductivity values at room temperature were measured to be $9.1 \pm 0.9 \mathrm{~W} \mathrm{~m}^{-1} \mathrm{~K}^{-1}, 11.8 \pm 1.2 \mathrm{~W} \mathrm{~m}^{-1} \mathrm{~K}^{-1}$, and $11.5 \pm 1.2 \mathrm{~W} \mathrm{~m}^{-1} \mathrm{~K}^{-1}$ for $\mathrm{Cu}_{0.65} \mathrm{Ni}_{0.35}, \mathrm{Cu}_{0.55} \mathrm{Ni}_{0.45}$, and $\mathrm{Cu}_{0.45} \mathrm{Ni}_{0.55}$, respectively. It is important to note that the alloys present different crystallite sizes with values of $27.4 \mathrm{~nm}$, $38.0 \mathrm{~nm}$, and $30.2 \mathrm{~nm}$ for $\mathrm{Cu}_{0.65} \mathrm{Ni}_{0.35}, \mathrm{Cu}_{0.55} \mathrm{Ni}_{0.45}$, and $\mathrm{Cu}_{0.45} \mathrm{Ni}_{0.55}$, respectively. The alloy with the highest $\mathrm{Cu}$ content presents the smallest crystallite size, while the two other alloys, with a different crystallite size, exhibit similar thermal conductivity values. In the literature, it can only be found a study where the thermal conductivity of non-nanocrystalline $\mathrm{Cu}_{0.55} \mathrm{Ni}_{0.45}$ material was measured, with a value of $29 \mathrm{~W} \mathrm{~m}^{-1} \mathrm{~K}^{-1}$ at $300 \mathrm{~K}$ and $60 \mathrm{~W} \mathrm{~m}^{-1} \mathrm{~K}^{-1}$ at $1100 \mathrm{~K}^{21}$ Comparing our results with those of the literature at room temperature, an increment of 3.2 times is observed. This reduction in the thermal conductivity of nanocrystalline CuNi is due to the decrease of the crystallite size of the CuNi bulk material and it is the reason why an increment in the figure of merit, 1.3 times more have been obtained in this work compared to the bulk.

Due to the high values of electrical conductivity for CuNi alloys, the Wiedemann-Franz law, $k_{\mathrm{e}}=\sigma \cdot L \cdot T$, where $L$ is the Lorenz number, has been used to differentiate between the phonons and electrons contribution of the thermal conductivity. For the calculation in Table 2, a Lorenz number of $2.44 \times 10^{-8} \mathrm{~W} \Omega \mathrm{K}^{-2}$, that is characteristic for metals ${ }^{39}$ were employed.

From Table 2, it is extracted that the contribution of the electrons, electronic thermal conductivity $\left(k_{\mathrm{e}}\right)$, is around $77-91 \%$ of the total thermal conductivity in our nanostructured $\mathrm{CuNi}$ alloys; while it is around $53 \%$ for the $\mathrm{Cu}_{0.55} \mathrm{Ni}_{0.45}$ bulk. ${ }^{21}$ This large reduction in the lattice thermal conductivity $\left(k_{1}\right)$ is due to the scattering of the phonons at the grain boundaries, achieving values of $k_{1}$ that are even two orders of magnitude lower than the $k_{1}$ for $\mathrm{Cu}_{0.55} \mathrm{Ni}_{0.45}$ bulk. ${ }^{21}$

\subsection{Stability of the thermoelectric properties of nanocrystalline CuNi alloys}

To study if the CuNi alloys are stable and the grain size is maintained, the alloys were cycled up to $500{ }^{\circ} \mathrm{C}$ to be sure that the properties did not change for $\mathrm{Cu}_{0.65} \mathrm{Ni}_{0.35}$, which is the alloy that exhibited the best properties. As an example, the first three cycles of the $\mathrm{Cu}_{0.65} \mathrm{Ni}_{0.35}$ alloys are shown in Fig. S3a-c of the ESI. $\dagger$ In this case, the electrical conductivity is more or less 
stable until $500{ }^{\circ} \mathrm{C}$, and the Seebeck coefficient and the power factor increase as the temperature increases, which is consistent with the previously reported results. Furthermore, the XRD (see Fig. S3d of the ESI $\dagger$ ), texture coefficients, and crystallite size after these measurements were analysed (see Table S2 in the ESI $\dagger$ ). This study shows that the alloys stay stable after cycling up to $500{ }^{\circ} \mathrm{C}$ and only a small increment in the crystallite size of $53 \mathrm{~nm}$ can be observed.

\section{Conclusions}

In conclusion, nanocrystalline CuNi alloys were obtained, and show an enhancement in their thermoelectric properties when compared to bulk CuNi alloys. Different compositions of $\mathrm{CuNi}$ were studied, and their efficiency for thermoelectric applications was improved by nanostructuration. By pulsed electrodeposition, it was possible to control the composition of $\mathrm{CuNi}$ by changing the applied current density. Nanocrystalline CuNi alloys were obtained with a crystallite size of approximately $30-40 \mathrm{~nm}$ through the addition of saccharine. The figure of merit was found to be $(5.5 \pm 1.5) \times 10^{-2},(6.1 \pm 1.4) \times 10^{-2}$, and $(5.9 \pm 1.4) \times 10^{-2}$ for $\mathrm{Cu}_{0.65} \mathrm{Ni}_{0.35}, \mathrm{Cu}_{0.55} \mathrm{Ni}_{0.45}$, and $\mathrm{Cu}_{0.45} \mathrm{Ni}_{0.55}$, respectively, which is 1.3 higher than the value reported for bulk CuNi. The thermal conductivity was reduced by 3.2 times compared to bulk due to the phonon scattering at the grain boundaries. This work shows that commercial alloys like $\mathrm{CuNi}$, which are nonpollutant, inexpensive, completely scalable to the industry, and more abundant elements than more conventional thermoelectric materials, are good candidates for thermoelectric applications. Additional ways to nanostructure these alloys must be addressed to reduce further the thermal conductivity.

\section{Conflicts of interest}

The authors declare no competing financial interest.

\section{Acknowledgements}

The authors would like to acknowledge financial support from MAT2017-86450-C4-3-R. C. V. M. acknowledges financial support from Juan de la Cierva Incorporación grants (IJCI-2017-31350) and P. C.-S. acknowledges financial support from CSIC JAEINT19_EX_0606 grant. We acknowledge the service from the MiNa Laboratory at IMN, and funding from CM (project SpaceTec, S2013/ICE2822), MINECO (project CSIC13-4E-1794), and EU (FEDER, FSE). We acknowledge support of the publication fee by the CSIC Open Access Publication Support Initiative through its Unit of Information Resources for Research (URICI).

\section{References}

1 E. Pellicer, A. Varea, S. Pané, B. J. Nelson, E. Menéndez, M. Estrader, S. Suriñach, M. D. Baró, J. Nogués and J. Sort, Adv. Funct. Mater., 2010, 20, 983-991.
2 A. Varea, E. Pellicer, S. Pané, B. J. Nelson, S. Suriñach, M. D. Baró and J. Sort, Int. J. Electrochem. Sci., 2012, 7, 1288-1302.

3 E. Pellicer, A. Varea, S. Pané, K. M. Sivaraman, B. J. Nelson, S. Suriñach, M. D. Baró and J. Sort, Surf. Coat. Technol., 2011, 205, 5285-5293.

4 L. Durivault, O. Brylev, D. Reyter, M. Sarrazin, D. Bélanger and L. Roué, J. Alloys Compd., 2007, 432, 323-332.

5 S.-G. Hur, D.-J. Kim, B.-D. Kang and S.-G. Yoon, J. Electrochem. Soc., 2005, 152, G472.

6 E. H. Williams, Phys. Rev., 1931, 38, 828-831.

7 Y. W. Huang, T.-Y. Chao, C. C. Chen and Y. T. Cheng, Appl. Phys. Lett., 2007, 90, 244105.

8 R. G. Delatorre, M. L. Sartorelli, A. Q. Schervenski, A. A. Pasa and S. Güths, J. Appl. Phys., 2003, 93, 6154-6158.

9 D. Beretta, N. Neophytou, J. M. Hodges, M. G. Kanatzidis, D. Narducci, M. Martin- Gonzalez, M. Beekman, B. Balke, G. Cerretti, W. Tremel, A. Zevalkink, A. I. Hofmann, C. Müller, B. Dörling, M. Campoy-Quiles and M. Caironi, Mater. Sci. Eng., R, 2019, 138, 100501.

10 N. Madar, T. Givon, D. Mogilyansky and Y. Gelbstein, J. Appl. Phys., 2016, 120, 035102.

11 Y. Gelbstein, J. Davidow, E. Leshem, O. Pinshow and S. Moisa, Phys. Status Solidi B, 2014, 251, 1431-1437.

12 D. Ben-Ayoun, Y. Sadia and Y. Gelbstein, J. Alloys Compd., 2017, 722, 33-38.

13 O. Meroz, D. Ben-Ayoun, O. Beeri and Y. Gelbstein, J. Alloys Compd., 2016, 679, 196-201.

14 C. V. Manzano, B. Abad, M. Muñoz Rojo, Y. R. Koh, S. L. Hodson, A. M. Lopez Martinez, X. Xu, A. Shakouri, T. D. Sands, T. Borca-Tasciuc and M. Martin-Gonzalez, Sci. Rep., 2016, 6, 19129.

15 C. V. Manzano, A. A. Rojas, M. Decepida, B. Abad, Y. Feliz, O. Caballero-Calero, D. A. Borca-Tasciuc and M. MartinGonzalez, J. Solid State Electrochem., 2013, 17, 2071-2078.

16 M. Muñoz Rojo, B. Abad, C. V. Manzano, P. Torres, X. Cartoixà, F. X. Alvarez and M. Martín Gonzalez, Nanoscale, 2017, 9, 6741-6747.

17 M. Muñoz Rojo, Y. Zhang, C. V. Manzano, R. Alvaro, J. Gooth, M. Salmeron and M. Martin-Gonzalez, Sci. Rep., 2016, 6, 19014-19018.

18 C. Rodríguez-Fernández, C. V. Manzano, A. H. Romero, J. Martín, M. Martín-González, M. J. Morais de Lima and A. Cantarero, Nanotechnology, 2016, 27, 075706.

19 C. V. Manzano, B. Abad and M. Martín-González, J. Electrochem. Soc., 2018, 165(14), D768-D773.

20 Y. Sadia, N. Madar, I. Kaler and Y. Gelbstein, J. Electron. Mater., 2015, 44, 1637-1643.

21 H. Muta, K. Kurosaki, M. Uno and S. Yamanaka, J. Alloys Compd., 2003, 359, 326-329.

22 Y. Shimizu, M. Mizoshiri, M. Mikami, J. Sakurai and S. Hata, J. Phys.: Conf. Ser., 2018, 1052, 012032.

23 A. Sugihara, M. Kodzuka, K. Yakushiji, H. Kubota, S. Yuasa, A. Yamamoto, K. Ando, K. Takanashi, T. Ohkubo, K. Hono and A. Fukushima, Appl. Phys. Exp., 2010, 3, 065204.

24 M. Martín-González, O. Caballero-Calero and P. Díaz-Chao, Renewable Sustainable Energy Rev., 2013, 24, 288-305. 
25 C. V. Manzano and M. Martín-González, Front. Chem., 2019, 7, 516.

26 C. V. Manzano, P. Schürch, L. Pethö, G. Bürki, J. Michler and L. Philippe, J. Electrochem. Soc., 2019, 166, E310-E316.

27 P. Schürch, R. Ramachandramoorthy, L. Pethö, J. Michler and L. Philippe, Appl. Mater. Today, 2020, 20, 100667.

28 O. Caballero-Calero, P. Díaz-Chao, B. Abad, C. V. Manzano, M. D. Ynsa, J. J. Romero, M. M. Rojo and M. S. MartínGonzález, Electrochim. Acta, 2014, 123, 117-126.

29 B. Abad, M. Rull-Bravo, S. L. Hodson, X. Xu and M. MartinGonzalez, Electrochim. Acta, 2015, 169, 37-45.

30 S. H. Ahn, H.-Y. Park, I. Choi, S. J. Yoo, S. J. Hwang, H.-J. Kim, E. Cho, C. W. Yoon, H. Park, H. Son, J. M. Hernandez, S. W. Nam, T.-H. Lim, S.-K. Kim and J. H. Jang, Int. J. Hydrogen Energy, 2013, 38, 13493-13501.
31 H. Natter, M. Schmelzer and R. Hempelmann, J. Mater. Res., 2011, 13, 1186-1197.

32 T. A. Green, A. E. Russell and S. Roy, J. Electrochem. Soc., 1998, 145, 875-881.

33 H. Hu, X. Wang and X. Xu, J. Appl. Phys., 1999, 86, 3953-3958.

34 B. Abad, J. Maiz and M. Martin-Gonzalez, J. Phys. Chem. C, 2016, 120, 5361-5370.

35 G. B. Harris, Philos. Mag., 1952, 43, 113-123.

36 B. Wiendlocha, Phys. Rev. B, 2018, 97, 205203.

37 C.-A. Wu, K.-C. Chang, F.-H. Lin, Z.-R. Yang, A. Gharleghi, T.-Z. Wei and C.-J. Liu, Chem. Eng. J., 2019, 368, 409-416.

38 T.-R. Wei, C.-F. Wu, F. Li and J.-F. Li, J. Materiom., 2018, 4, 304-320.

39 H.-S. Kim, Z. M. Gibbs, Y. Tang, H. Wang and G. J. Snyder, APL Mater., 2015, 3, 041506. 